the modes of treatment for this condition is extensive but a mention of the recent work with calcitonin might be included in the next edition. There is also an excellent evaluation of galvanic stimulation for denervated muscle with a refreshing conclusion as to its proper use in the recovery stage and the firm rejection of amputation as the best treatment for the flail limb is well argued from long and wide experience. The section of the rheumatoid hand shows perhaps undue optimism regarding the outcome of surgery in some respects, that on the stiff hand is of very high quality and those on principles of rehabilitation and on resettlement reinforce the view that this is a book which every occupational therapy and physiotherapy department should own and every physician in rheumatology or rehabilitation should read for sheer pleasure-but ensure that he has his own separate copy!

The book is superbly produced, the illustrations are a model of clarity and the type-face makes for ease of reading even for the visually handicapped, in short it cannot be too highly recommended.

A. G. White Department of Rheumatology, Whittington Hospital, London
Tutorials in Clinical Rheumatology

By Douglas N. Golding. Pp. 140. Pitman, London, 1981. £5.95.

I enjoyed reading this little book. This is probably because it is always interesting to peer, metaphorically speaking, over a colleague's shoulder to see how his clinical practice compares with one's own: a sort of clinical voyeurism. The author takes a modified problem-orientated approach to discuss patients with quite common problems and certainly on looking through the book I came across many familiar rheumatic problems.

The book is aimed at undergraduates, MRCP candidates, the early period of rheumatology specialist training and possibly general practitioners. It would not be much help to casualty officers who rather badly need a very concise guide dealing with casualty department rheumatic problems. I think this book succeeds in its aim and will be a useful but limited addition to the literature.

M. L. Snaith

Department of Rheumatology, University College Hospital,

London

\title{
Royal Postgraduate Medical School
}

(University of London)

\section{European Cardiology at the Hammersmith : 1982 Growing Points in Cardiology 10-14 May 1982 \\ Organised by the Division of Cardiovascular Diseases}

The Course will concentrate on new aspects of diagnosis and treatment which will be surveyed by experts at the Royal Postgraduate Medical School and by visiting lecturers.

Topics to be covered will include:

Radionuclides and scanning techniques

Prostaglandins in cardiology

Exercise testing

Percutaneous transluminal coronary angioplasty

Reperfusion and fibrinolysis

New aspects of hypertension

Arrhythmias

One hour each day will be devoted to "Meet the Experts" sessions, and the last day to practical sessions visiting laboratories.

\section{Course fee:}

\section{Application forms may be obtained from:}

A limited number of scholarships will be available.
$£ 100$ (for home students and members of the EEC) $£ 340$ (for overseas students)

School Office (SSC)

Royal Postgraduate Medical School

Hammersmith Hospital

Du Cane Road

London WI2 OHS

Telephone: 0I-743 2030 ext 35I 